\title{
Notch signaling in the pathogenesis, progression and identification of potential targets for cholangiocarcinoma (Review)
}

\author{
PEERANATE VANAROJ $^{1}$, WANNA CHAIJAROENKUL ${ }^{1}$ and KESARA NA-BANGCHANG $^{1,2}$ \\ ${ }^{1}$ Graduate Program in Bioclinical Sciences, Chulabhorn International College of Medicine, Thammasat University; \\ ${ }^{2}$ Center of Excellence in Pharmacology and Molecular Biology of Malaria and Cholangiocarcinoma, \\ Thammasat University, Pathumthani, 12120 Thailand
}

Received September 3, 2021; Accepted January 3, 2022

DOI: $10.3892 / \mathrm{mco} .2022 .2499$

\begin{abstract}
Cholangiocarcinoma (CCA) is an aggressive type of bile duct cancer that is characterized by a high mortality rate due to its late diagnosis and ineffective treatment. The aim of the present systematic review was to analyze the association between Notch signaling and CCA in terms of its pathogenesis, progression and potential treatment targets. Relevant information was gathered from the PubMed, ScienceDirect and Scopus databases using the search terms 'cholangiocarcinoma' AND 'Notch signaling'. Of the 90 articles identified, 28 fulfilled the eligibility criteria and were included in the analysis. It was concluded that overexpression/upregulation of Notch ligands, such as Jagged1 and Notch receptors (Notch1, Notch2 and Notch3), as well as upregulation of the upstream Notch signaling pathway, promoted CCA development and progression. In addition, downregulation of Notch1 signaling through several possible interventions appears to be a promising strategy for inhibition of CCA development and progression. Therefore, the Notch signaling pathway may be considered as a potential target for CCA control.
\end{abstract}

\section{Introduction}

Cholangiocarcinoma (CCA) is a bile duct cancer with a high mortality rate. A significant proportion of the CCA cases and resultant mortalities worldwide are reported in the northeastern region of Thailand, where the major risk factor is infection by the liver fluke Opisthorchis viverrini through the consumption of improperly cooked cyprinoid fish that contain the parasite (1). There are currently no specific biomarkers for early detection of early-stage CCA, and patients are usually

Correspondence to: Dr Kesara Na-Bangchang, Graduate Program in Bioclinical Sciences, Chulabhorn International College of Medicine, Thammasat University, 99 Moo 18, Paholyothin Road, Klonglung, Pathumthani, 12120 Thailand

E-mail: kesaratmu@yahoo.com

Key words: cholangiocarcinoma, Notch signaling, Notch1, Notch2, Notch3 diagnosed when the disease has already progressed to the advanced stage, resulting in a poor prognosis. Liver resection is the standard therapy, but is not suitable for all cases. The 5-year survival rate following liver resection is $<20 \%$, depending on the aggressiveness, metastatic propensity and invasiveness of the tumors. Furthermore, CCA is resistant to chemotherapy and radiation (2). Investigation of the molecular mechanisms underlying the pathogenesis and progression of CCA has been an ongoing research focus, and several signaling molecules and pathways have been demonstrated to be involved in the pathogenesis and progression of CCA (3).

The Notch signaling pathway has been proposed as a conservative pathway that plays a key role in cell differentiation, proliferation and apoptosis (4). This signaling pathway is associated with several receptors and ligands. The four identified receptors are Notch1, Notch2, Notch3 and Notch4. The two families of ligands involved are the Delta-like family (DLL1, DLL3 and DLL4), and the Jagged family (Jagged1 and Jagged2). The activation of Notch signaling relies on two proteolytic enzymes in the a disintegrin and metalloprotease (ADAM) families and $\gamma$-secretase enzyme, which cleaves Notch receptors into two domains, i.e., Notch extracellular domain (NECD) and Notch intracellular domain (NICD). Following cleavage, NICD translocates to the nucleus and binds to transcription factors to promote expression of target genes, such as members of the hairy and enhancer of split (Hes) and Hes-related to YRPW motif (Hey) families (5).

Overexpression of Notch signaling genes is associated with the proliferation of certain cancers, including ovarian and breast cancers and glioma (6-8). However, overexpression of Notch signaling genes can also result in cancer cell apoptosis, such as in cases of liver cancer, small cell lung cancer and melanoma (9-11). The Notch signaling pathway in CCA cells is summarized in Fig. 1. The objectives of the present systematic review were to analyze the association of Notch signaling with the pathogenesis and progression of CCA, and uncover potential molecular targets for CCA control.

\section{Materials and methods}

The present systematic review was performed by combining the search results from three databases, i.e., PubMed, ScienceDirect and Scopus. The search terms applied were 
'cholangiocarcinoma' AND 'Notch signaling'. All articles were retrieved and downloaded to the EndNote X9 database (Thomson Reuters Company, Canada) for further analysis. They were initially screened by titles and abstracts to exclude irrelevant articles (those not involving CCA or the Notch signaling pathway). Full-text articles included after the initial screening were further evaluated by applying the predefined eligibility criteria. The inclusion criteria were as follows: i) Articles published between January 2004 and March 2020; ii) articles available as full-text articles in English; and iii) articles with in vitro/in vivolex vivo studies related to the Notch signaling pathway in CCA alone or CCA and hepatocellular carcinoma (HCC). The exclusion criteria were as follows: i) Articles related to other diseases or types of cancer; ii) articles related to pathways other than Notch signaling; iii) duplicated articles; or iv) review articles, letters to the editor, editorials, systematic analyses or meta-analyses.

Two reviewers extracted data independently and disparities were resolved by discussion and suggestions from the third reviewer. The information extracted for analysis included: First author's name and year of publication, objective(s) of the study, type of Notch receptor investigated, type of study (in vitro, in vivo and ex vivo), type of cell lines or animals used, laboratory techniques used, and key results and conclusions.

\section{Results}

A total of 89 articles from PubMed, ScienceDirect and Scopus databases were downloaded to the EndNote database. A total of 54 articles were excluded, and further analysis of the titles and abstracts of the remaining 36 articles led to the exclusion of 8 articles ( 5 articles unrelated to CCA, and 3 articles unrelated to the Notch signaling pathway in CCA). Finally, 27 articles were included in the analysis. The flow diagram of the study selection process is presented in Fig. 2, and the study summary is provided in Tables I and II. The associations of Notch1 and Notch2 signaling with CCA development and progression were investigated in 6 articles each, while those of Notch 3 and Notch 4 signaling were investigated in 3 and 1 article(s), respectively. The investigations involved in vitro $(\mathrm{n}=8)$, in vivo $(\mathrm{n}=12)$ and ex vivo $(\mathrm{n}=8)$ studies. The effects of modulators of Notch signaling as potential chemotherapeutic targets for CCA were investigated in 10, 5, 3 and 3 articles for Notch1, Notch2, Notch3 and Notch4 signaling pathways, respectively. The investigated modulators included cinobufagin, verteporfin-photodynamic therapy (PDT), $\gamma$-secretase inhibitor (GSI), $\gamma$-secretase inhibitor IX, endocannabinoids, corilagin, short hairpin (sh)RNA, and small-molecule inhibitors (SMIs) of aspartate- $\beta$-hydroxylase, anti-Notch1,2,3 and Jagged1, microRNA (miRNA)-34a, PIK3-catalytic subunit alpha (PIK3CA), PIK75, verteporfin, FLI-06, microfibrillarassociated protein 5 (MFAP5), ALW-II-41-27, ephrin A1, lymphotoxin $\beta$ receptor (LT $\beta$ R), xanthohumol and $\gamma$-secretase inhibitor $\mathrm{N}$-[N-(3,5-difluorophenacetyl)-L-alanyl]S-phenylglycine t-butyl ester (DAPT) (Table II).

\section{Discussion}

A summary of the currently available information on the association between Notch signaling and the pathogenesis and progression of CCA, including modulators (inhibitors or stimulators) of the signaling pathway as potential candidates for CCA chemotherapeutics, is presented in Fig. 3 .

Upregulation of Notch signaling has been proposed as the mechanism associated with the transformation of mature hepatocytes into CCA cells (12-14). Nevertheless, activation of Notch signaling in hepatic progenitor cells, but not the transformation of hepatocytes, is proposed as the mechanism underlying CCA development (15). Increased expression of Notch1 has been linked to CCA development and progression (14,16-24). Notch1 has also been associated with cyclin E, the coordinate regulator protein in the G1 phase of the cell cycle; additionally, cyclin E can induce DNA damage (15). Increased NICD1 expression has also been associated with CCA development and progression through upregulation of cyclin E-associated DNA damage $(15,25)$. Furthermore, Notch1 and Notch2 signaling have been reported to play a critical role in CCA formation (12-14,24,26-29), in which Jagged1 is the specific ligand. Upregulation of PIK3CA, AKT, and Jagged1 directly activates Notch 2 signaling and induces CCA development. Overexpression of Jagged1 enhances Notch2 signaling (26), while anti-Jagged1 treatment suppresses Notch2 signaling $(27,28,30,31)$. At this time, the information on Notch3 and its role in CCA development and progression arelimited $(24,32)$. Notch 4 signaling has also been reported to promote the development of intrahepatic CCA (ICC) and is associated with a poor survival rate (24).

The activation of upstream Notch signaling molecules, including Yes-associated protein (YAP), AKT, mTOR, SNAIL and PIK3CA, are key processes that stimulate CCA formation through the transformation of mature hepatocytes into CCA cells (12). AKT is the main upstream Notch signaling molecule, which upregulates Notch1 and Notch2 $(12-14,26,27,29,33)$. mTOR is another upstream activator of the Notch1 receptor $(12,16)$. YAP is an upstream signaling molecule for both AKT and mTOR (12), and co-expression of YAP with AKT induces CCA development through activating Notch signaling via the Notch2 receptor and Jagged1 ligand $(12,14,28,34)$, or with co-expression of NICD and shp53 (shRNA of p53) (35). Co-expression of AKT and Ras (the protein product of the oncogene KRAS2), on the other hand, induces tumorigenesis $(21,27,29)$. MFAP5, enhanced green fluorescent protein-positive cells, mTOR and AKT, activate Notch signaling by increasing Notch1 expression, thereby enhancing CCA cell proliferation $(12,16,17)$. Modulation of mutant genes, such as p53 (inactivation), isocitrate dehydrogenase1 (activation), or other pathways, such as the Wnt ( $\beta$-catenin) pathway (activation), and the Myc pathway (activation) with co-expression of Notch signaling (activation) has been reported to induce CCA development $(14,25,33,36)$. Upregulation of Notch1 expression may also be caused by additional factors, such as a high expression level of presenilin 1 (37). Aspartate $\beta$-hydroxylase (ASPH) enhances activation of Notch signaling and stimulates CCA cell proliferation and migration. A high expression level of Notch1 can activate Ras-related C3 botulinum toxin substrate 1, which promotes CCA cell invasion and migration. ephrin type-A receptor 2 enhances the expression level of Notch1 and promotes CCA growth through the activation of AKT/RAS and by promoting lymphatic metastasis in ICC (21). 


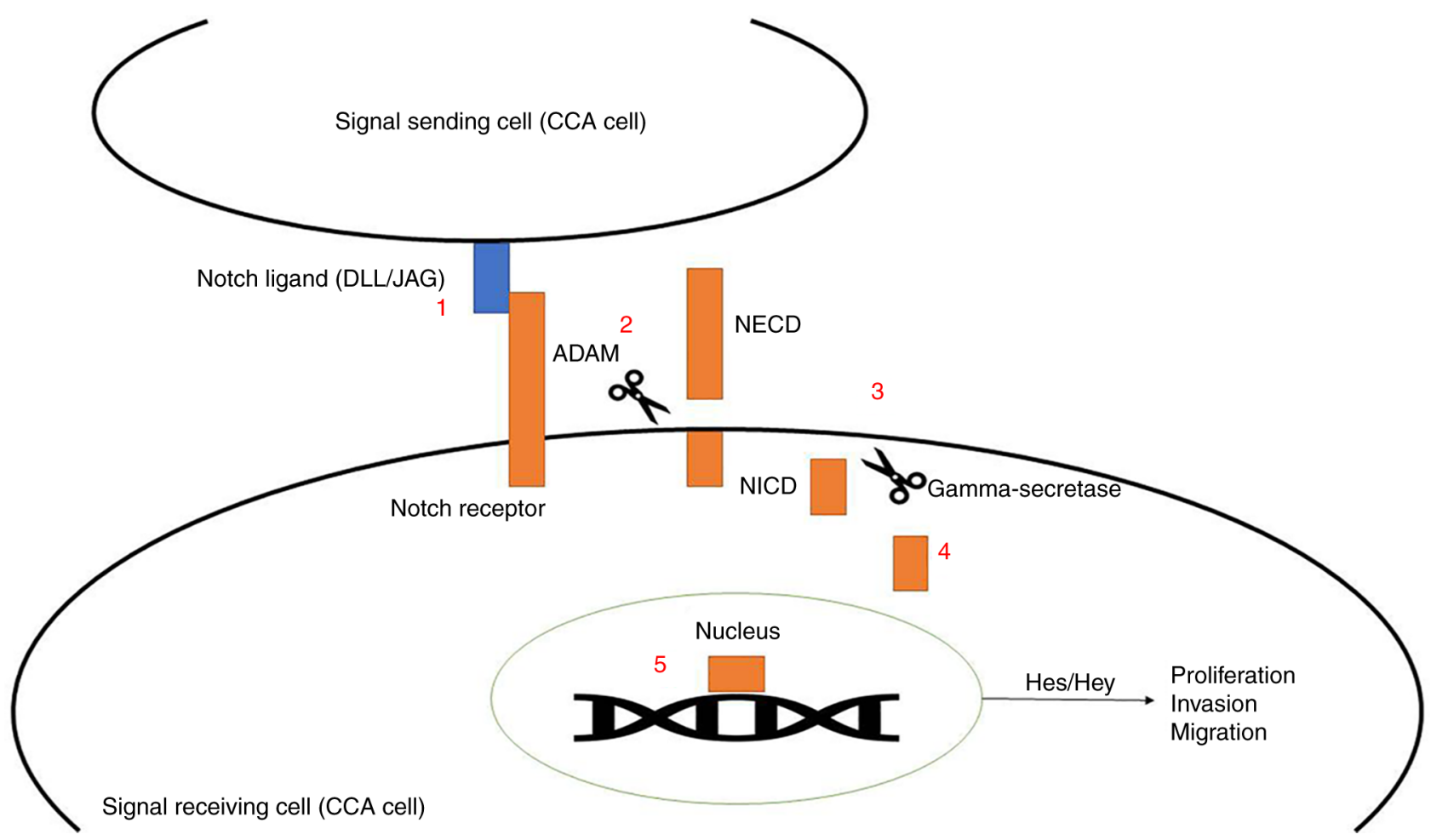

Figure 1. Notch signaling pathway in CCA cells. Notch ligands, such as members of the DLL or the JAG family, attach to the Notch receptors to activate the ADAM and $\gamma$-secretase enzymes. The ADAM cleaves NECD outside the cell membrane and the $\gamma$-secretase enzyme cleaves the NICD inside of the cell membrane. After being cleaved, the NICD translocates to the nucleus and interacts with the DNA-binding protein to promote expression of the target genes, such as Hes and Hey, which are associated with proliferation, migration and, invasion of CCA cells. CCA, cholangiocarcinoma; Hes, hairy and enhancer of split; Hey, Hes-related to YRPW motif; ADAM, a disintegrin and metalloprotease; NECD, Notch extracellular domain; NICD, Notch intracellular domain; DLL, delta-like family; JAG, Jagged family.

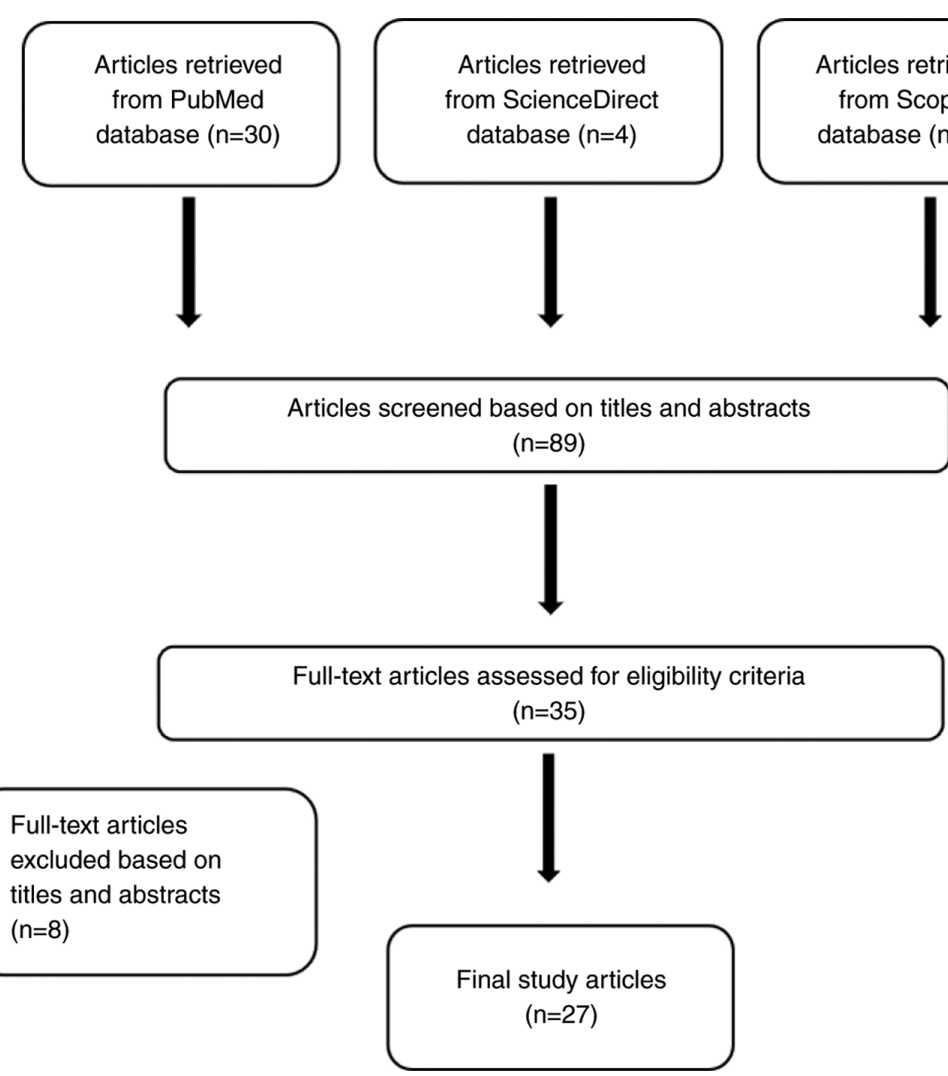

Figure 2. Flow diagram of study identification and selection process. A total of 90 articles were selected by the title and abstract by using the key words 'cholangiocarcinoma' AND 'Notch signaling.' A total of 54 articles were excluded (duplication, review articles, or non-full-text articles). A total of 8 articles were further excluded by the titles and abstracts, and 24 articles were finally included in the analysis. 


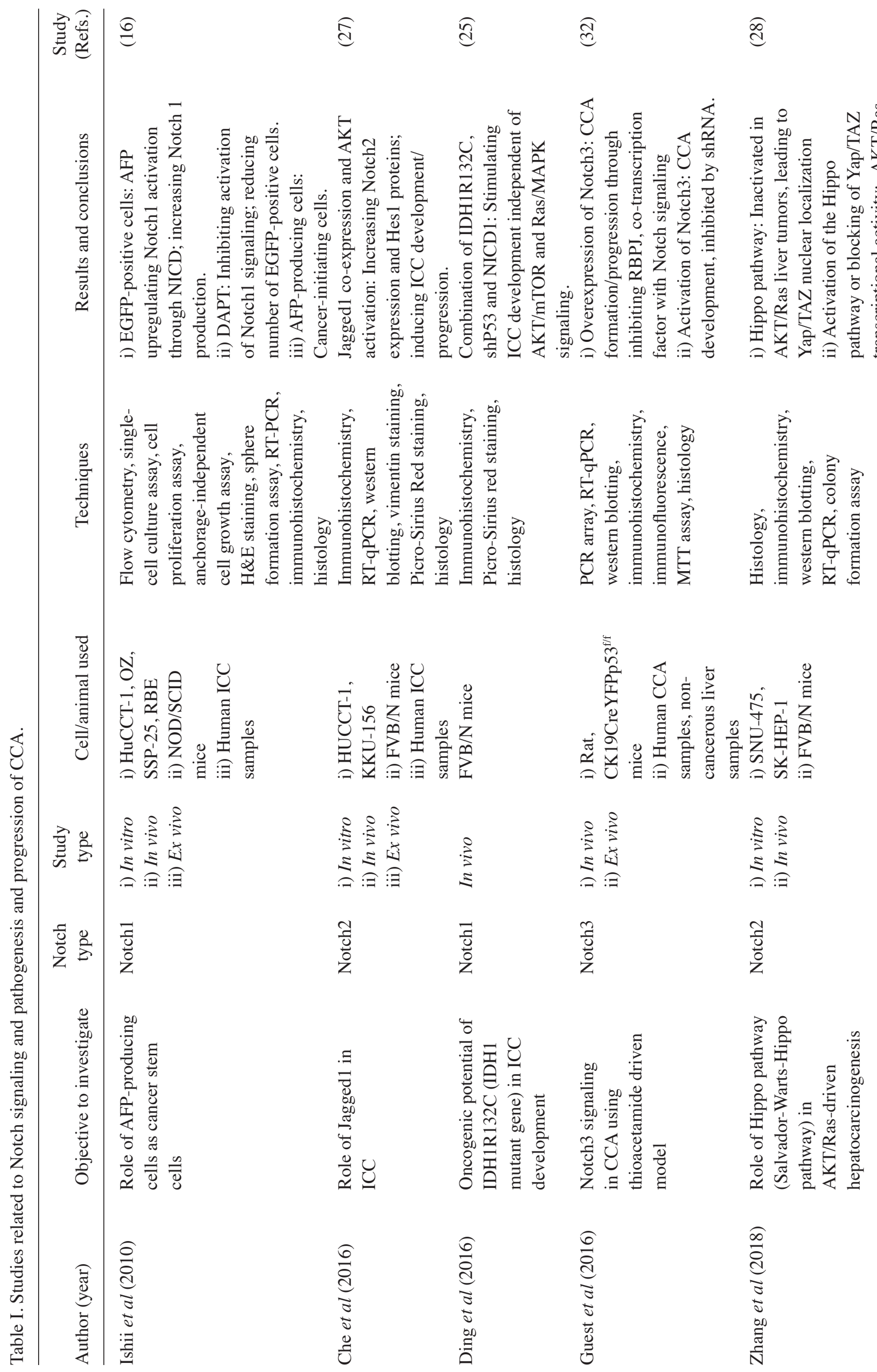




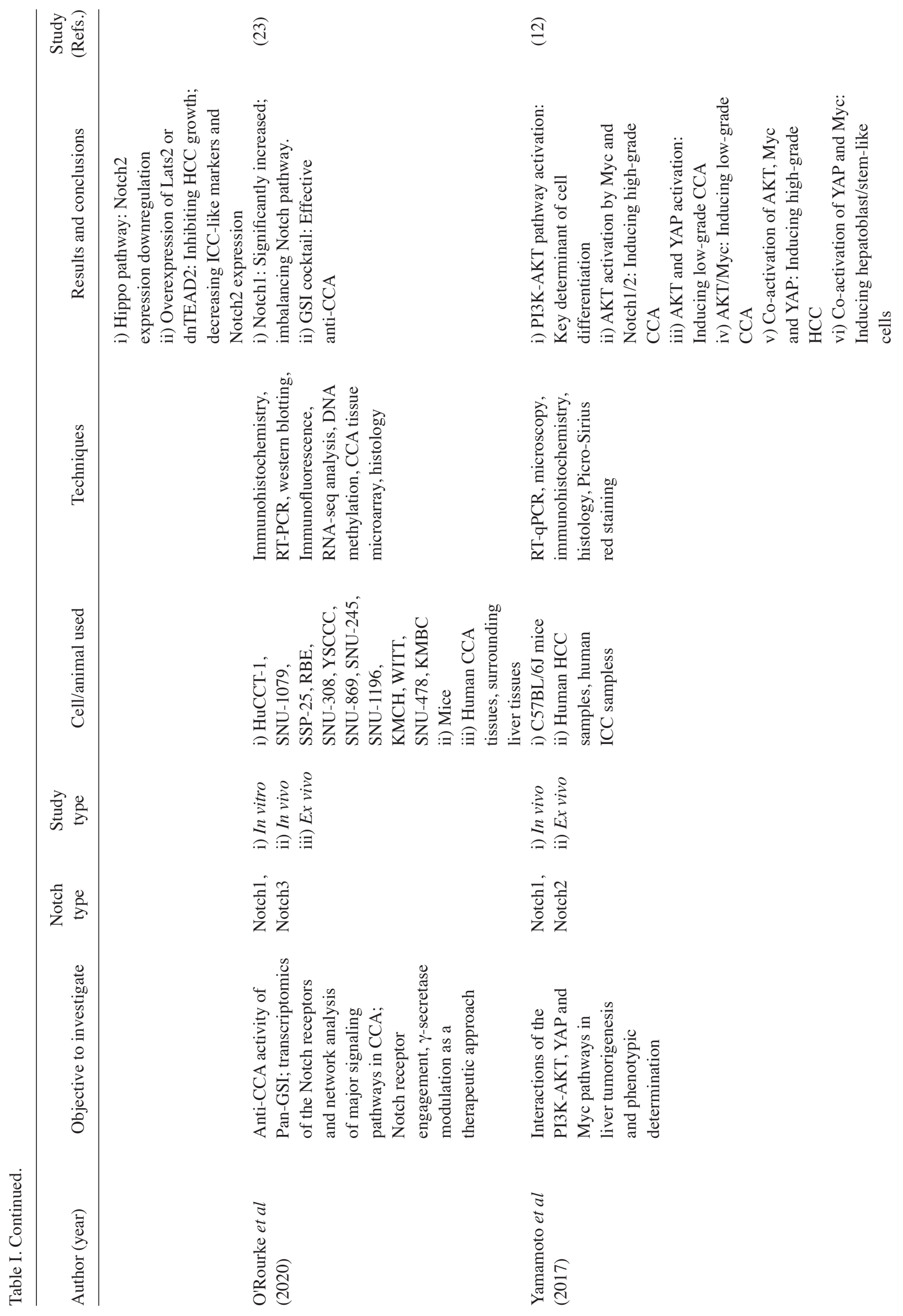




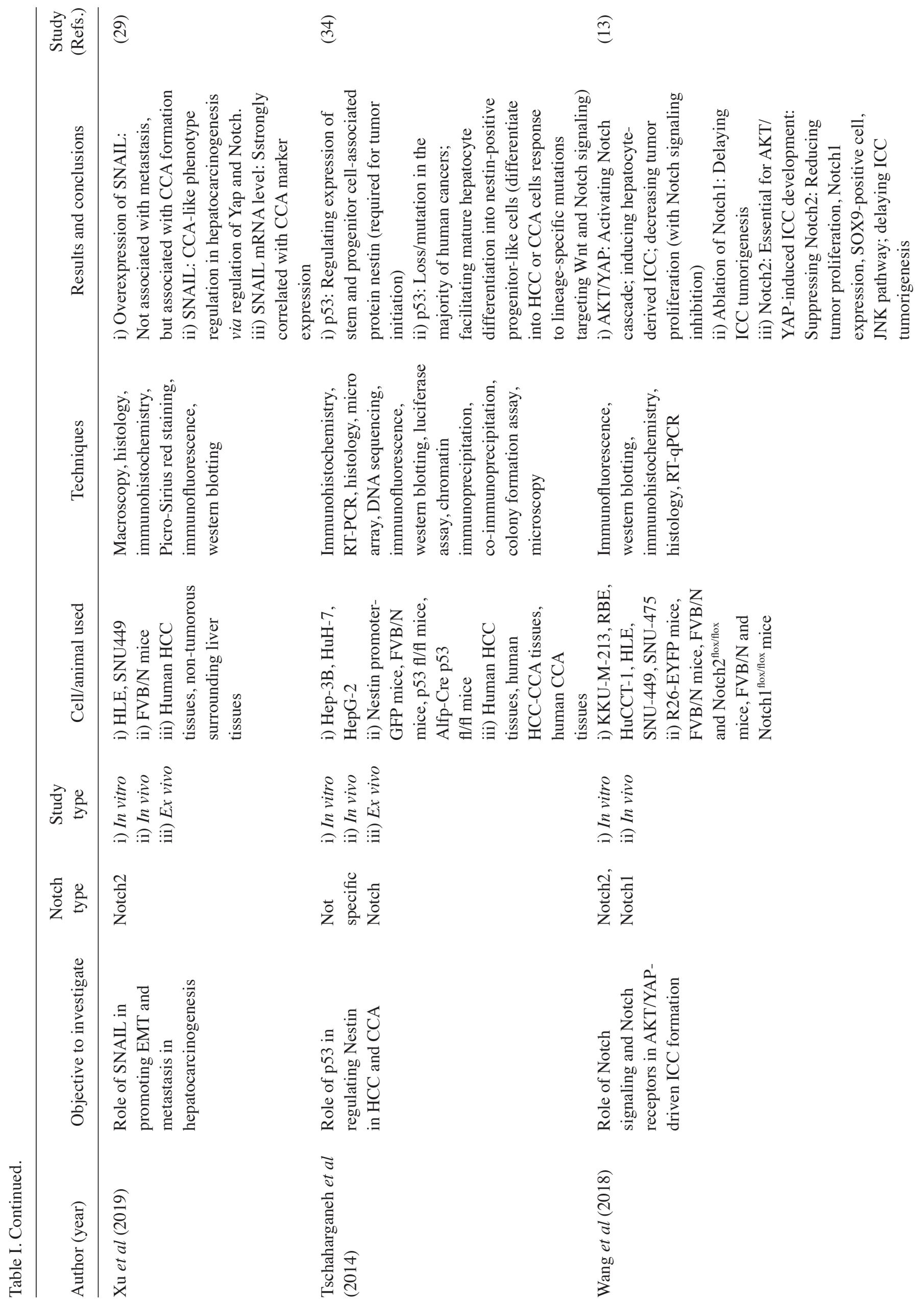




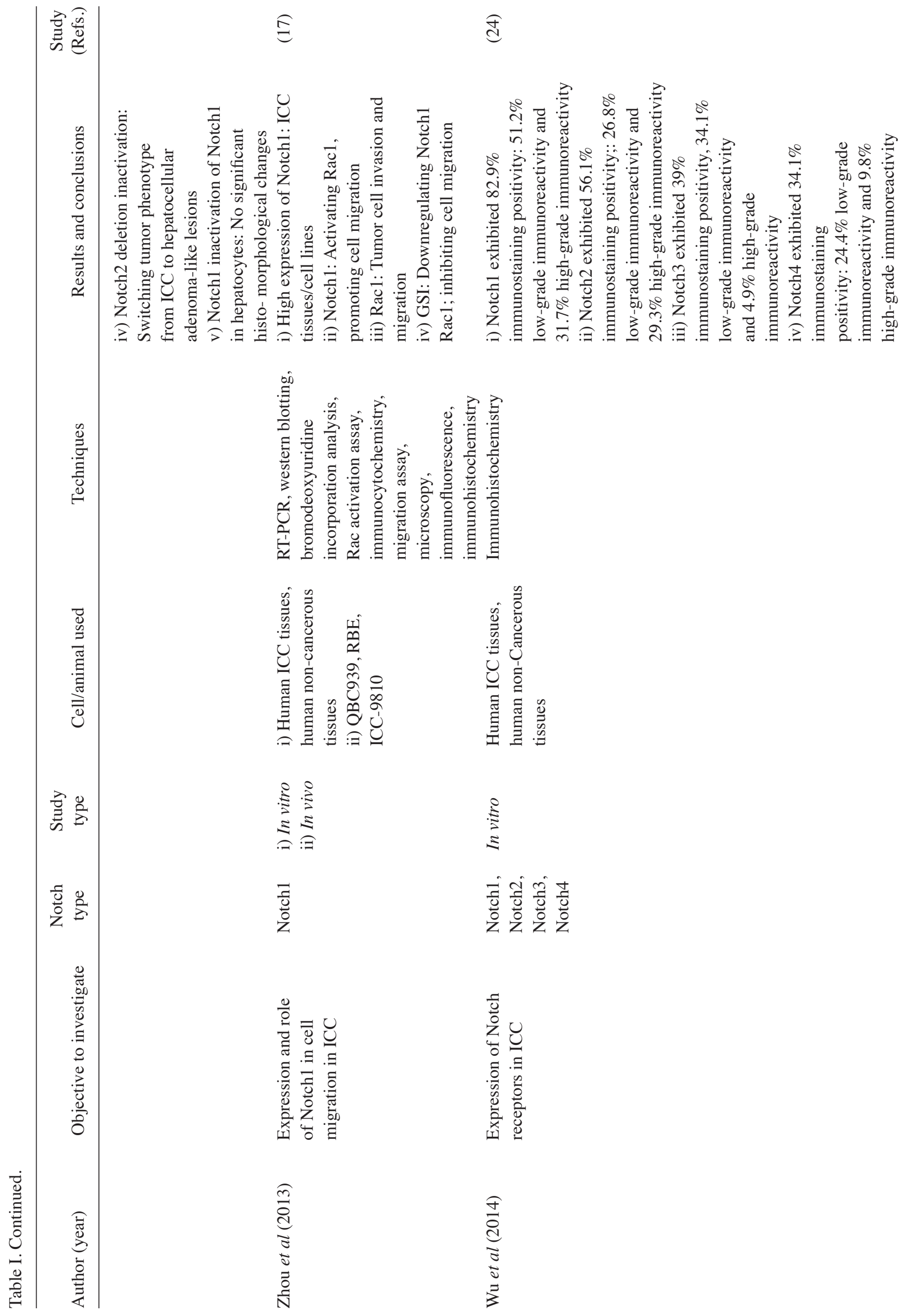


The role of Notch signaling in cancer pathogenesis and progression has also been demonstrated in several other types of cancer, including embryonal carcinoma (38), glioblastoma (39), melanoma (40), ependymoma (41), breast cancer (42), HCC (34), ovarian cancer (43), endometrial carcinoma (44), esophageal squamous cell carcinoma, gonadotroph pituitary adenomas (42), rhabdomyosarcoma (45), colon cancer (46), gastric cancer (47), gastrointestinal stromal tumors (48), anaplastic thyroid cancer (49), medullary thyroid cancer (50), pancreatic cancer (51), glioblastoma multiforme (52) and neuroendocrine neoplasms (53). The signaling molecules and pathways involved vary according to the type of cancer. Notch3, in addition to Notch1, appears to play an important role in breast cancer development and progression through its activation of cartilage oligomeric matrix protein expression (54).

Downregulation of Notch1 signaling by several interventions has been demonstrated to be a promising strategy for inhibition of CCA growth. These interventions include administration of cinobufagin (a traditional Chinese medicine extracted from parotid and skin glands of Chinese Toad) (21), xanthohumol (55), verteporfin-PDT (30), DAPT (23), PIK75 (PIK3CA-specific inhibitor), verteporfin, anti-Notch1 antibody (27), miRNA-34a (31) and small interfering (si)RNA LT $\beta R$ (22). The downregulation of Notch1 siRNA expression reduces Notch1 levels, which results in inhibition of Notch signaling, suppression of cell proliferation, and promotion of apoptosis $(20,22,27,30,31,55)$. Verteporfin-PDT downregulates the mRNA expression of Notch1, Notch2 and Jagged1 (30); additionally, verteporfin can reduce YAP levels, decrease cell proliferation and induce apoptosis (14). Inhibition of MFAP5 using the $\gamma$-secretase inhibitor FLI-06 also suppressed Notch1 expression in CCA (20). Inhibition of Notch2 signaling using anti-Notch2 or anti-Jagged1 antibodies also suppressed Notch2 signaling (27) and miRNA-34a expression (31). Direct inhibition of Notch2 using miRNA-34a, PDT, anti-Notch2 or anti-Jagged1, and the Hippo pathway cascade decreases Notch 2 levels, promotes apoptosis and inhibits cell proliferation. However, Notch1 and Notch2 signaling have been demonstrated to interact antagonistically with each other $(27,36)$. Antagonists of Notch1 signaling can enhance Notch2 signaling, while Notch2 depletion can increase the levels of various components of the Notch1 signaling pathway, such as the endocannabinoids anandamide (AEA) and 2-arachidonylglycerol (2-AG), or anti-Notch1 and anti-Notch2 antibodies (27,34). AEA and 2-AG have been shown to exert different effects on Notch signaling. AEA, which has antiproliferative activity, upregulates Notch1 signaling via increasing the level of presenilin1, a catalytic subunit of $\gamma$-secretase. On the other hand, 2-AG, which has growth-promoting activity, upregulates Notch2 signaling via increasing the expression of presenilin 2, another catalytic subunit of $\gamma$-secretase. 2-AG activates Notch2 and enhances CCA cell proliferation (36). There have only been a limited number of studies related to Notch 3 and its role in CCA, although is has been shown that using gene knockout or shRNA and SMIs to decrease Notch3 levels suppresses CCA growth (32). Both shRNA and SMIs inhibit ASPH and Notch signaling to suppress CCA cell proliferation and migration (56). 


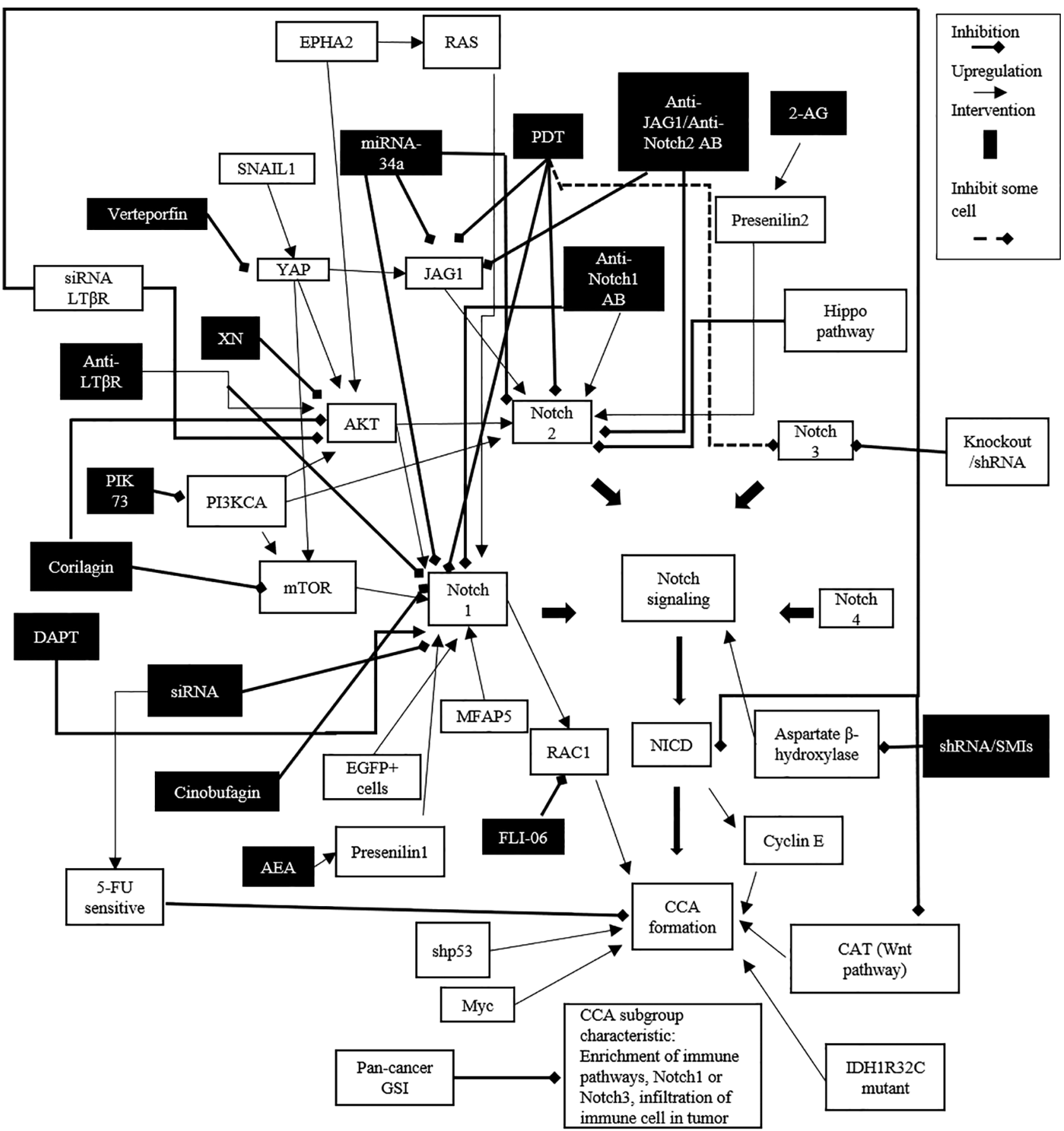

Figure 3. Notch signaling and ist association with the pathogenesis, progression and chemotherapeutic targets in CCA. Notch receptors, such as Notch1, Notch2, Notch3 and Notch4, activate the Notch signaling pathway and promote CCA formation via NICD. The upstream signals of Notch, such as mTOR, PI3KCA, AKT, YAP and SNAIL, can promote the effects of the Notch signaling pathway by increasing Notch receptor expression levels. A direct ligand of Notch2, such as JAG1, can also upregulate Notch2 expression and can be upregulated by YAP. Notch1 can be induced by MFAP5 and is found in EGFP ${ }^{+}$cells. Moreover, Notch1 can activate RAC1 to promote CCA formation, or induce NICD to increase cyclin E expression to promote CCA formation. Several interventions downregulate the expression of Notch receptors and suppress Notch signaling, including anti-LT $\beta R$, verteporfin, corilagin, XN, PDT, cinobufagin, PIK73, siRNA, shRNA/SMIs, DAPT, miRNA-34a and FLI-06. In addition, some modulators can inhibit certain Notch receptors but promote different Notch receptors, such as AEA, 2-AG, anti-Notch1 antibody, anti-Notch2 antibody and anti-JAG1 antibody. Some pathways, including the Hippo pathway, decrease Notch receptor expression levels, while others, such as the Wnt pathway, can promote CCA formation. CCA, cholangiocarcinoma; NICD, Notch intracellular domain; YAP, Yes-associated protein; PI3KCA, PIK3-catalytic subunit alpha; MFAP5, microfibrillar-associated protein 5; EGFP, enhanced green fluorescent protein-positive; RAC1, Ras-related C3 botulinum toxin substrate 1; LT $\beta$ R, lymphotoxin $\beta$ receptor; PDT, photodynamic therapy; siRNA, small inhibitory RNA; shRNA, short hairpin RNA; SMIs, small-molecule inhibitors; DAPT, $\gamma$-secretase inhibitor N-[N-(3,5-difluorophenacetyl)-L-alanyl]-S-phenylglycine t-butyl ester; miRNA, microRNA; AEA, anandamide; 2-AG, 2-arachidonylglycerol; XN, xanthohumol.

The potential of the aforementioned interventions for the control of other types of cancer has also been demonstrated. These include cinobufagin for osteosarcoma (57), xanthohumol for hepatocarcinoma (58), FLI-06 for tongue cancer (59), GSI for glioblastoma cancer stem cells (60), T-cell for acute lymphoblastic leukemia (61), osteosarcoma (62) and 


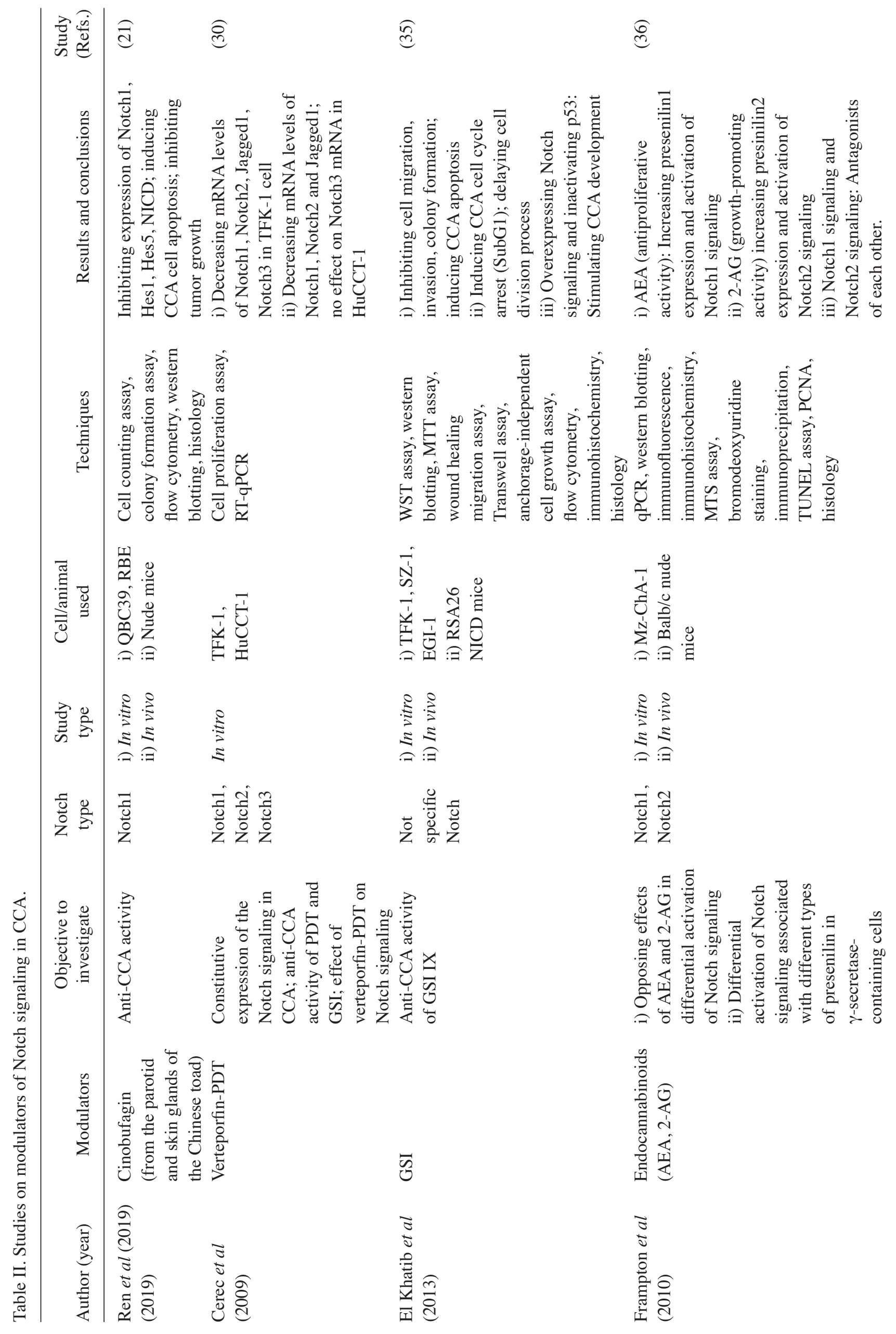




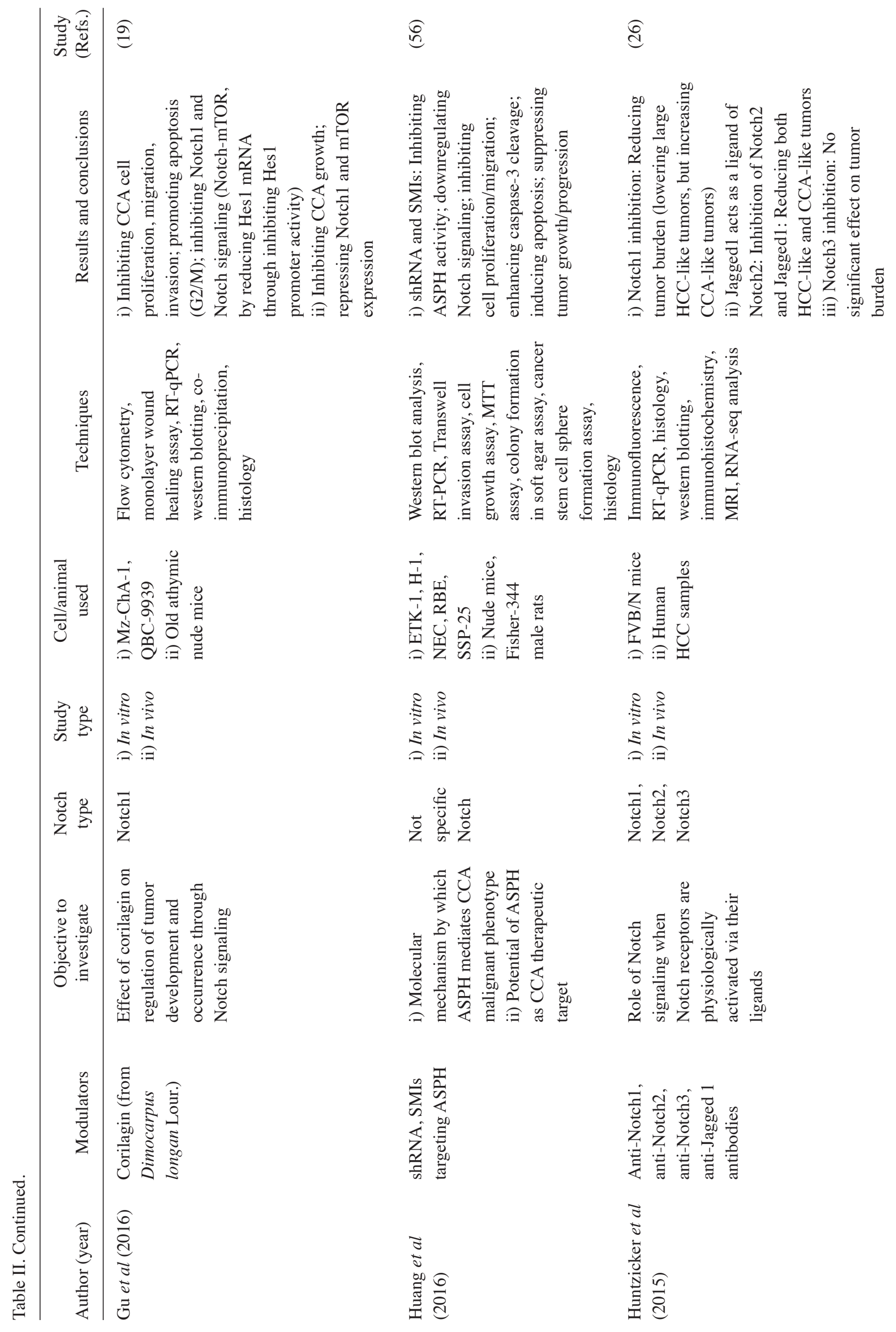




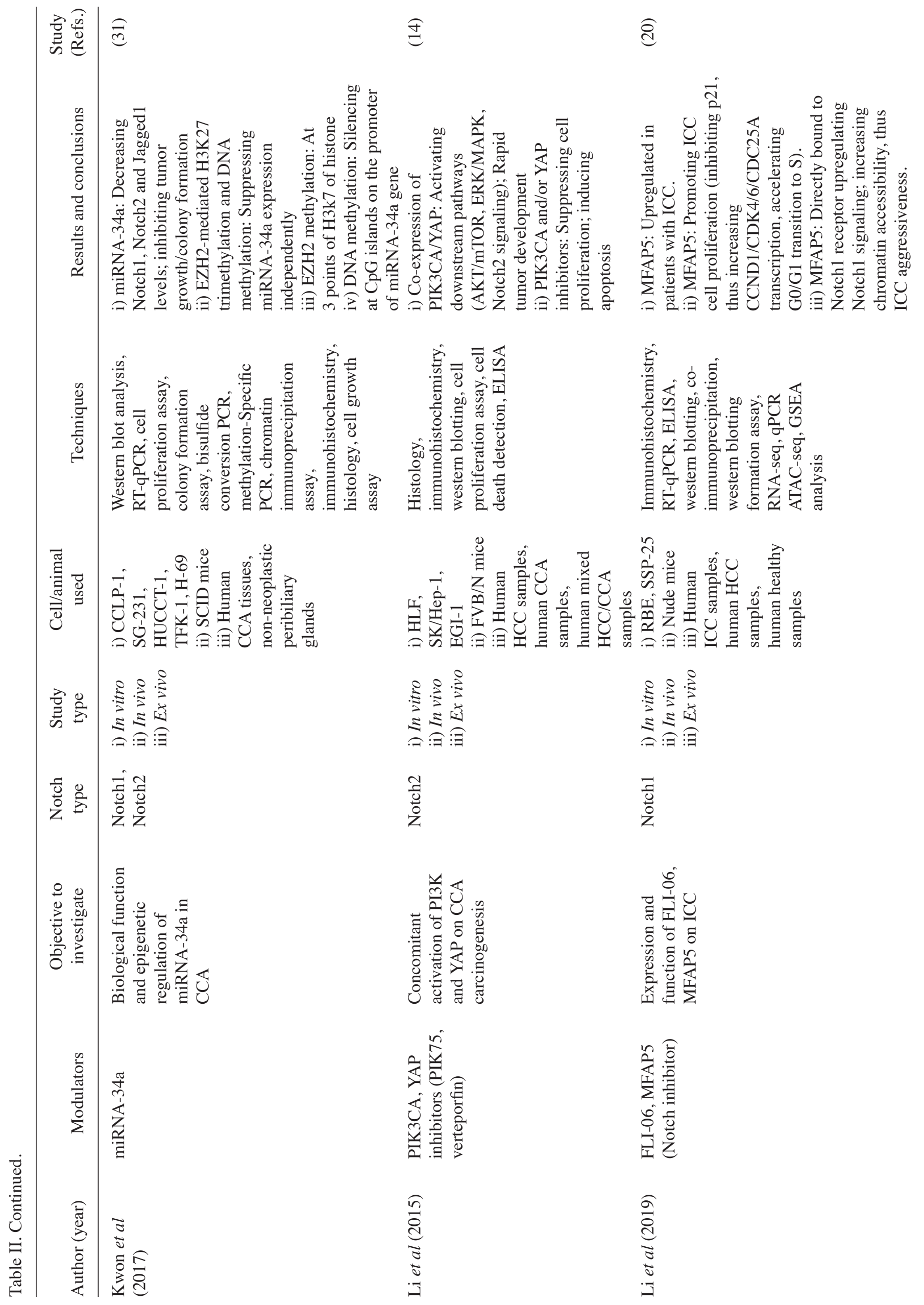




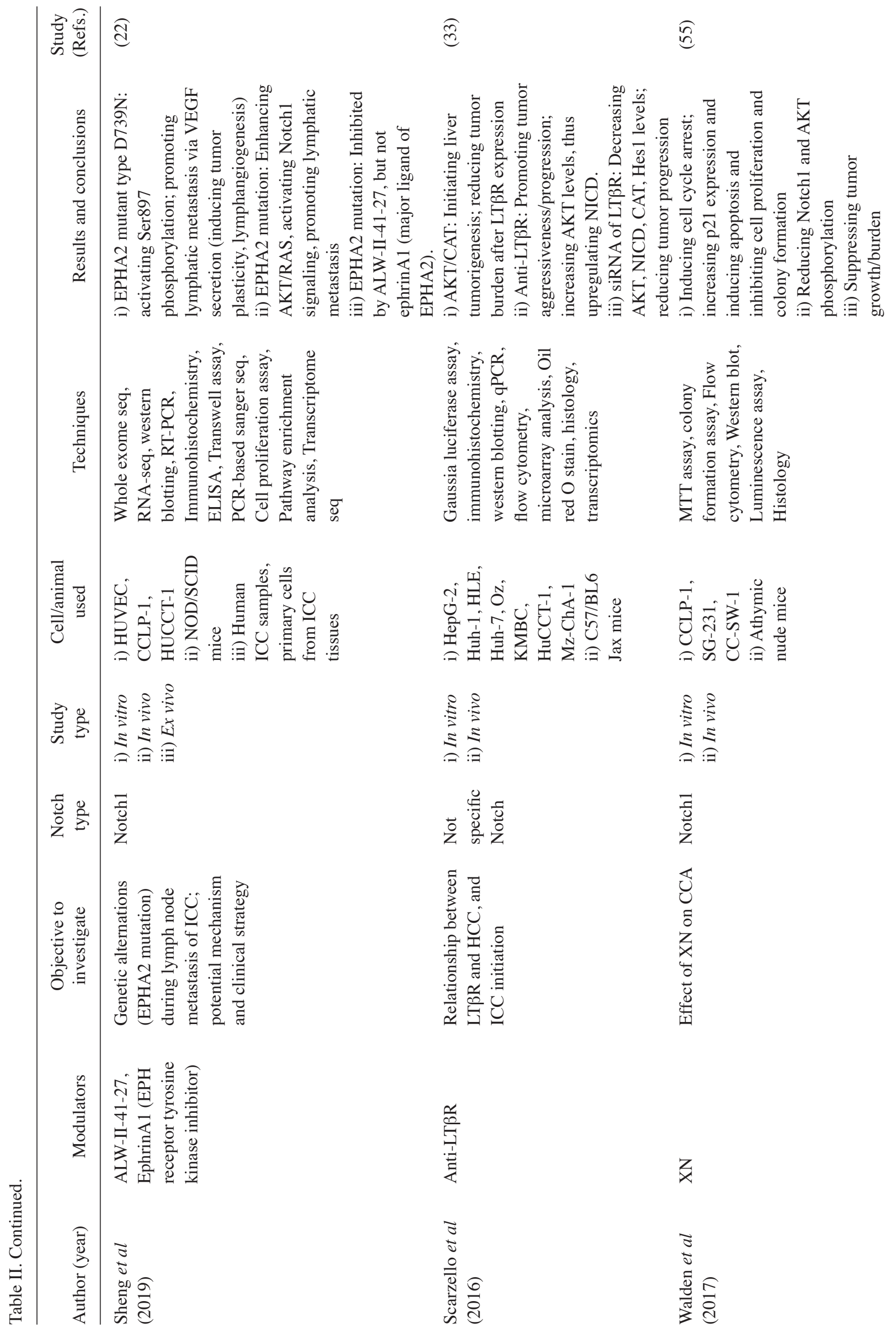




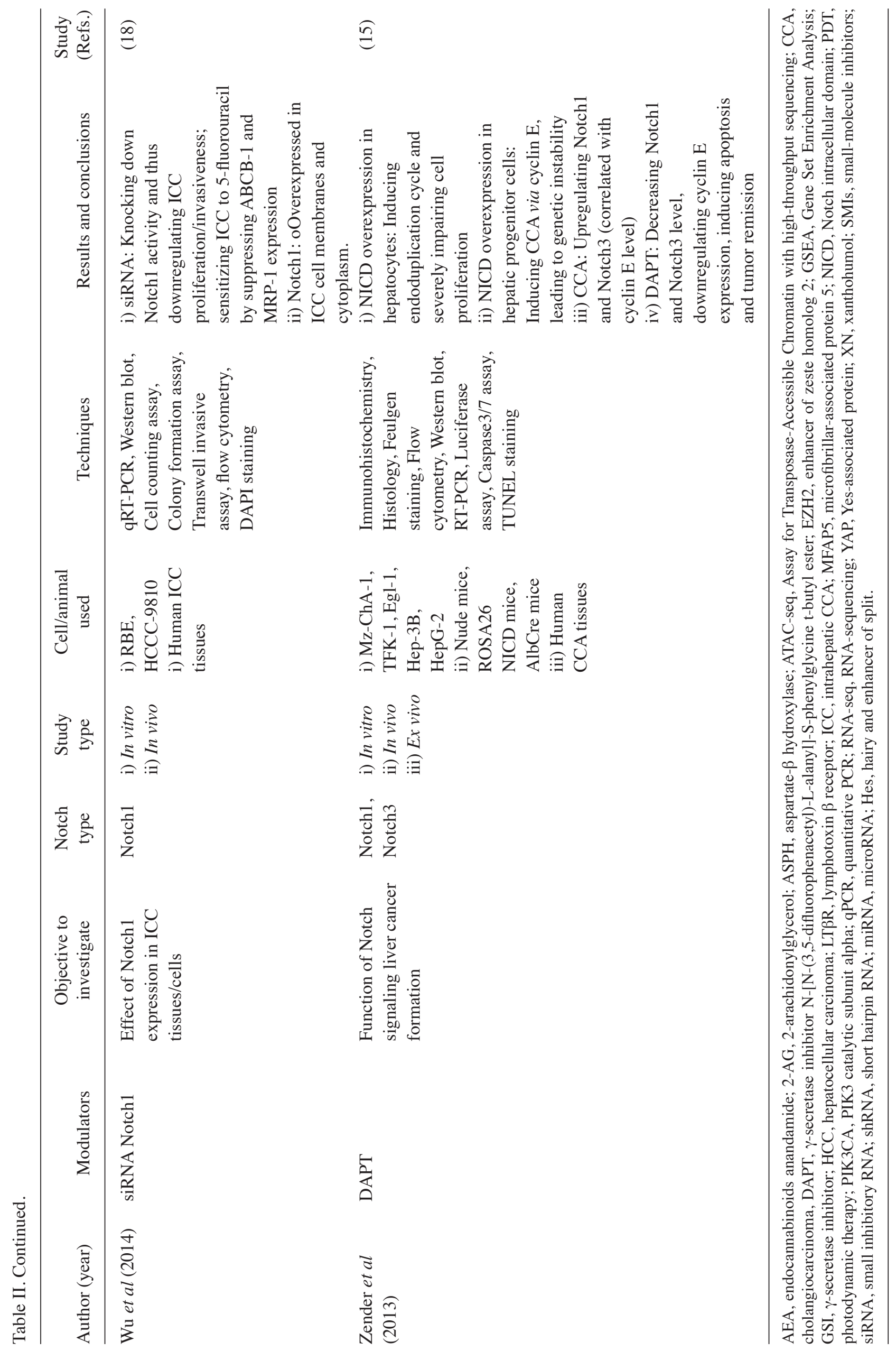


triple-negative breast cancer (63), and DAPT for glioma (64), colorectal cancer (65), cervical cancer (66), gastric cancer (67), head/neck squamous cell carcinoma (68), osteosarcoma (69), choriocarcinoma (70) and ovarian cancer (71). In addition, miRNA-34a has also been reported to inhibit the progression of pancreatic cancer and medulloblastoma $(72,73)$, and siRNA interference has been reported to inhibit cell proliferation in glioblastoma multiforme (74).

In summary, overexpression/upregulation of the expression of Notch ligands (e.g., Jagged1) and Notch receptors (Notch1, Notch2, Notch3 and Notch4), as well as upregulation of the expression of upstream Notch signaling molecules, promotes CCA development and progression. Therefore, downregulation of Notch1 signaling through several interventions is a promising strategy for inhibition of CCA development and progression. However, further studies focusing on the application of these modulators of Notch signaling in a clinical setting must be performed in the future.

\section{Acknowledgements}

The authors thank Mr. Ethan Vindvamara (American molecular biologist; Graduate Program in Bioclinical Sciences, Chulabhorn International College of Medicine, Thammasat University, Pathumthani, Thailand) for English editing of the manuscript.

\section{Funding}

The study was supported by the Research Team Promotion Grant, National Research Council of Thailand (grant no. NRCT 820/2563), Thammasat University (Center of Excellence in Pharmacology and Molecular Biology of Malaria and Cholangiocarcinoma) and Thammasat University Research Fund (contract no. TUFT 65/2564).

\section{Availability of data and materials}

Data sharing is not applicable to this article, as no datasets were generated or analyzed during the current study.

\section{Authors' contributions}

PV, WC and KN conceived the study and analyzed and interpreted the data. PN performed the background research, collected the data and wrote the manuscript. WC and KN critically revised the manuscript for important intellectual content. Data authentication is not applicable. All the authors have read and approved the final manuscript.

\section{Ethics approval and consent to participate}

Not applicable.

\section{Patient consent for publication}

Not applicable.

\section{Competing interests}

All the authors declare that they have no competing interests.

\section{References}

1. Khan SA, Tavolari S and Brandi G: Cholangiocarcinoma: Epidemiology and risk factors. Liver Int 39 (Suppl 1): S19-S31, 2019.

2. Mao Y, Huang X, Shuang Z, Lin G, Wang J, Duan F, Chen J and Li S: PARP inhibitor olaparib sensitizes cholangiocarcinoma cells to radiation. Cancer Med 7: 1285-1296, 2018.

3. Papoutsoglou P, Louis C and Coulouarn C: Transforming growth factor-beta (TGFbeta) signaling pathway in cholangiocarcinoma. Cells 8: 960, 2019.

4. Pancewicz-Wojtkiewicz J: Epidermal growth factor receptor and notch signaling in non-small-cell lung cancer. Cancer Med 5: 3572-3578, 2016.

5. Kandasamy K, Mohan SS, Raju R, Keerthikumar S, Kumar GS, Venugopal AK, Telikicherla D, Navarro JD, Mathivanan S, Pecquet C, et al: NetPath: A public resource of curated signal transduction pathways. Genome Biol 11: R3, 2010.

6. Hopfer O, Zwahlen D, Fey MF and Aebi S: The Notch pathway in ovarian carcinomas and adenomas. Br J Cancer 93: 709-718, 2005.

7. Stockhausen MT, Kristoffersen K and Poulsen HS: The functional role of Notch signaling in human gliomas. Neuro Oncol 12: 199-211, 2010.

8. Kontomanolis EN, Kalagasidou S, Pouliliou S, Anthoulaki X, Georgiou N,Papamanolis V and FasoulakisZN: The notch pathway in breast cancer progression. ScientificWorldJournal 2018: 2415489, 2018.

9. Huang Q, Li J, Zheng J and Wei A: The carcinogenic role of the notch signaling pathway in the development of hepatocellular carcinoma. J Cancer 10: 1570-1579, 2019.

10. Sriuranpong V, Borges MW, Ravi RK, Arnold DR, Nelkin BD, Baylin SB and Ball DW: Notch signaling induces cell cycle arrest in small cell lung cancer cells. Cancer Res 61: 3200-3205, 2001.

11. Shao H, Cai L, Grichnik JM, Livingstone AS, Velazquez OC and Liu ZJ: Activation of Notch1 signaling in stromal fibroblasts inhibits melanoma growth by upregulating WISP-1. Oncogene 30: 4316-4326, 2011

12. Yamamoto M, Xin B, Watanabe K, Ooshio T, Fujii K, Chen X, Okada Y, Abe H, Taguchi Y, Miyokawa N, et al: Oncogenic determination of a broad spectrum of phenotypes of hepatocyte-derived mouse liver tumors. Am J Pathol 187: 2711-2725, 2017.

13. Wang J, Dong M, Xu Z, Song X, Zhang S, Qiao Y, Che L, Gordan J, Hu K, Liu Y, et al: Notch2 controls hepatocyte-derived cholangiocarcinoma formation in mice. Oncogene 37: 3229-3242, 2018.

14. Li X, Tao J, Cigliano A, Sini M, Calderaro J, Azoulay D, Wang C, Liu Y, Jiang L, Evert K, et al: Co-activation of PIK3CA and Yap promotes development of hepatocellular and cholangiocellular tumors in mouse and human liver. Oncotarget 6: 10102-10115, 2015.

15. Zender S, Nickeleit I, Wuestefeld T, Sörensen I, Dauch D, Bozko P, El-Khatib M, Geffers R, Bektas H, Manns MP, et al: A critical role for notch signaling in the formation of cholangiocellular carcinomas. Cancer Cell 23: 784-795, 2013.

16. Ishii T, Yasuchika K, Suemori H, Nakatsuji N, Ikai I and Uemoto S: Alpha-fetoprotein producing cells act as cancer progenitor cells in human cholangiocarcinoma. Cancer Lett 294: 25-34, 2010.

17. Zhou Q, Wang Y, Peng B, Liang L and Li J: The roles of Notch1 expression in the migration of intrahepatic cholangiocarcinoma. BMC Cancer 13: 244, 2013.

18. Wu WR, Zhang R, Shi XD, Zhu MS, Xu LB, Zeng H and Liu C: Notch1 is overexpressed in human intrahepatic cholangiocarcinoma and is associated with its proliferation, invasiveness and sensitivity to 5-fluorouracil in vitro. Oncol Rep 31: 2515-2524, 2014.

19. Gu Y, Xiao L, Ming Y, Zheng Z and Li W: Corilagin suppresses cholangiocarcinoma progression through Notch signaling pathway in vitro and in vivo. Int J Oncol 48: 1868-1876, 2016.

20. Li JH, Zhu XX, Li FX, Huang CS, Huang XT, Wang JQ, Gao ZX, Li SJ, Xu QC, Zhao W and Yin XY: MFAP5 facilitates the aggressiveness of intrahepatic Cholangiocarcinoma by activating the Notch1 signaling pathway. J Exp Clin Cancer Res 38: 476, 2019.

21. Ren J, Wang S, Jin L, Ma F, Zhou D and Cai Q: Cinobufagin inhibits tumor growth by inducing apoptosis through Notch signaling pathways in human cholangiocarcinoma. Transl Cancer Res 8: 2461-2469, 2019. 
22. Sheng Y, Wei J, Zhang Y, Gao X, Wang Z, Yang J, Yan S, Zhu Y, Zhang Z, Xu D, et al: Mutated EPHA2 is a target for combating lymphatic metastasis in intrahepatic cholangiocarcinoma. Int J Cancer 144: 2440-2452, 2019.

23. O'Rourke CJ, Matter MS, Nepal C, Caetano-Oliveira R, Ton PT, Factor VM and Andersen JB: Identification of a pan-gamma-secretase inhibitor response signature for notchdriven cholangiocarcinoma. Hepatology 71: 196-213, 2020.

24. Wu WR, Shi XD, Zhang R, Zhu MS, Xu LB, Yu XH, Zeng H, Wang J and Liu C: Clinicopathological significance of aberrant Notch receptors in intrahepatic cholangiocarcinoma. Int J Clin Exp Pathol 7: 3272-3279, 2014.

25. Ding N, Che L, Li XL, Liu Y, Jiang LJ, Fan B, Tao JY, Chen X and Ji JF: Oncogenic potential of IDH1R132C mutant in cholangiocarcinoma development in mice. World J Gastroenterol 22: 2071-2080, 2016

26. Huntzicker EG, Hötzel K, Choy L, Che L, Ross J, Pau G, Pau G Sharma N, Siebel CW, Chen X and French DM: Differential effects of targeting Notch receptors in a mouse model of liver cancer. Hepatology 61: 942-952, 2015.

27. Che L, Fan B, Pilo MG, Xu Z, Liu Y, Cigliano A, Cossu A, Palmieri G, Pascale RM, Porcu A, et al: Jagged 1 is a major Notch ligand along cholangiocarcinoma development in mice and humans. Oncogenesis 5: e274, 2016.

28. Zhang S, Wang J, Wang H, Fan L, Fan B, Zeng B, Tao J, Li X, Che L, Cigliano A, et al: Hippo cascade controls lineage commitment of liver tumors in mice and humans. Am J Pathol 188: 995-1006, 2018

29. Xu M, Wang J, Xu Z, Li R, Wang P, Shang R, Cigliano A, Ribback S, Solinas A, Pes GM, et al: SNAIL promotes the cholangiocellular phenotype, but not epithelial-mesenchymal transition, in a murine hepatocellular carcinoma model. Cancer Res 79: 5563-5574, 2019.

30. Cerec V, Andreola F and Pereira S: Effect of verteporfin-PDT on the Notch signaling pathway in cholangiocarcinoma (CCA) cell lines: SPIE; 7380, Photodynamic Therapy: Back to the Future, 73806J 2009

31. Kwon H, Song K, Han C, Zhang J, Lu L, Chen W and Wu T: Epigenetic Silencing of miRNA-34a in human cholangiocarcinoma via EZH2 and DNA methylation: Impact on regulation of notch pathway. Am J Pathol 187: 2288-2299, 2017.

32. Guest RV, Boulter L, Dwyer BJ, Kendall TJ, Man TY, Minnis-Lyons SE, Lu WY, Robson AJ, Gonzalez SF, Raven A, et al: Notch3 drives development and progression of cholangiocarcinoma. Proc Natl Acad Sci USA 113: 12250-12255, 2016.

33. Scarzello AJ, Jiang Q, Back T, Dang H, Hodge D, Hanson C, Subleski J, Weiss JM, Stauffer JK, Chaisaingmongkol J, et al: LT $\beta R$ signalling preferentially accelerates oncogenic AKT-initiated liver tumours. Gut 65: 1765-1775, 2016

34. Tschaharganeh DF, Xue W, Calvisi DF, Evert M, Michurina TV, Dow LE, Banito A, Katz SF, Kastenhuber ER, Weissmueller S, et al: p53-dependent Nestin regulation links tumor suppression to cellular plasticity in liver cancer. Cell 158 : 579-592, 2014

35. El Khatib M, Bozko P, Palagani V, Malek NP, Wilkens L and Plentz RR: Activation of Notch signaling is required for cholangiocarcinoma progression and is enhanced by inactivation of p53 in vivo. PLoS One 8: e77433, 2013.

36. Frampton G, Coufal M, Li H, Ramirez J and DeMorrow S: Opposing actions of endocannabinoids on cholangiocarcinoma growth is via the differential activation of Notch signaling. Exp Cell Res 316: 1465-1478, 2010

37. Fox V, Gokhale PJ, Walsh JR, Matin M, Jones M and Andrews PW: Cell-cell signaling through NOTCH regulates human embryonic stem cell proliferation. Stem Cells 26: 715-723, 2008

38. Chen J, Kesari S, Rooney C, Strack PR, Chen J, Shen H, Wu L and Griffin JD: Inhibition of notch signaling blocks growth of glioblastoma cell lines and tumor neurospheres. Genes Cancer 1: $822-835,2010$

39. Balint K, Xiao M, Pinnix CC, Soma A, Veres I, Juhasz I, Brown EJ, Capobianco AJ, Herlyn M and Liu ZJ: Activation of Notch1 signaling is required for beta-catenin-mediated human primary melanoma progression. J Clin Invest 115: 3166-3176, 2005.

40. Puget S, Grill J, Valent A, Bieche I, Dantas-Barbosa C, Kauffmann A, Dessen P, Lacroix L, Geoerger B, Job B, et al: Candidate genes on chromosome 9q33-34 involved in the progression of childhood ependymomas. J Clin Oncol 27: 1884-1892, 2009.
41. Chen J, Chang H, Peng X, Gu Y, Yi L, Zhang Q, Zhu J and Mi M 3,6-dihydroxyflavone suppresses the epithelial-mesenchymal transition in breast cancer cells by inhibiting the Notch signaling pathway. Sci Rep 6: 28858, 2016

42. Wang X, Wu B and Zhong Z: Downregulation of YAP inhibits proliferation, invasion and increases cisplatin sensitivity in human hepatocellular carcinoma cells. Oncol Lett 16: 585-593, 2018

43. Wei X, Jia Y, Lou H, Ma J, Huang Q, Meng Y, Sun C, Yang Z, Li X, Xu S, et al: Targeting YAP suppresses ovarian cancer progression through regulation of the PI3K/Akt/mTOR pathway. Oncol Rep 42: 2768-2776, 2019.

44. Götte M, Greve B, Kelsch R, Müller-Uthoff H, Weiss K, Kharabi Masouleh B, Sibrowski W, Kiesel L and Buchweitz O: The adult stem cell marker Musashi-1 modulates endometrial carcinoma cell cycle progression and apoptosis via Notch-1 and p21WAF1/CIP1. Int J Cancer 129: 2042-2049, 2011.

45. Cheng C, Cui H, Zhang L, Jia Z, Song B, Wang F, Li Y, Liu J, Kong P, Shi R, et al: Genomic analyses reveal FAM84B and the NOTCH pathway are associated with the progression of esophageal squamous cell carcinoma. Gigascience 5: 1, 2016

46. De Salvo M, Raimondi L, Vella S, Adesso L, Ciarapica R, Verginelli F, Pannuti A, Citti A, Boldrini R, Milano GM, et al: Hyper-activation of Notch3 amplifies the proliferative potential of rhabdomyosarcoma cells. PLoS One 9: e96238, 2014.

47. Singh S, Arcaroli J, Chen Y, Thompson DC, Messersmith W, Jimeno A and Vasiliou V: ALDH1B1 is crucial for colon tumorigenesis by modulating Wnt/ $\beta$-catenin, notch and PI3K/Akt signaling pathways. PLoS One 10: e0121648, 2015.

48. Zhang XS, Hu YH, Gao HY, Lan XW and Xue YW: Downregulation of Notch1 inhibits the invasion and metastasis of human gastric cancer cells SGC7901 and MKN74 in vitro through PTEN activation and dephosphorylation of Akt and FAK. Mol Med Rep 16: 2318-2324, 2017.

49. Dumont AG, Yang Y, Reynoso D, Katz D, Trent JC and Hughes DP: Anti-tumor effects of the Notch pathway in gastrointestinal stromal tumors. Carcinogenesis 33: 1674-1683, 2012.

50. Yu XM, Phan T, Patel PN, Jaskula-Sztul R and Chen H: Chrysin activates Notch1 signaling and suppresses tumor growth of anaplastic thyroid carcinoma in vitro and in vivo. Cancer 119: 774-781, 2013.

51. Jaskula-Sztul R, Pisarnturakit P, Landowski M, Chen H and Kunnimalaiyaan M: Expression of the active Notch1 decreases MTC tumor growth in vivo. J Surg Res 171: 23-27, 2011.

52. Dong X, Lin Q, Aihara A, Li Y, Huang CK, Chung W, Tang Q, Chen X, Carlson R, Nadolny C, et al: Aspartate $\beta$-Hydroxylase expression promotes a malignant pancreatic cellular phenotype. Oncotarget 6: 1231-1248, 2015.

53. Sturla LM, Tong M, Hebda N, Gao J, Thomas JM, Olsen M and de la Monte SM: Aspartate- $\beta$-hydroxylase (ASPH): A potential therapeutic target in human malignant gliomas. Heliyon 2: e00203, 2016.

54. Adler JT, Hottinger DG, Kunnimalaiyaan M and Chen H: Histone deacetylase inhibitors upregulate Notch-1 and inhibit growth in pheochromocytoma cells. Surgery 144: 956-961; discussion 961-2, 2008.

55. Walden D, Kunnimalaiyaan S, Sokolowski K, Clark TG and Kunnimalaiyaan M: Antiproliferative and apoptotic effects of xanthohumol in cholangiocarcinoma. Oncotarget 8: 88069-88078, 2017.

56. Huang CK, Iwagami Y, Aihara A, Chung W, de la Monte S, Thomas JM, Olsen M, Carlson R, Yu T, Dong X and Wands J: Anti-Tumor effects of second generation $\beta$-Hydroxylase inhibitors on cholangiocarcinoma development and progression. PLoS One 11: e0150336, 2016.

57. Cao Y, Yu L, Dai G, Zhang S, Zhang Z, Gao T and Guo W: Cinobufagin induces apoptosis of osteosarcoma cells through inactivation of Notch signaling. Eur J Pharmacol 794: 77-84, 2017.

58. Sun Z, Zhou C, Liu F, Zhang W, Chen J, Pan Y, Ma L, Liu Q, $\mathrm{Du}$ Y, Yang $J$ and Wang Q: Inhibition of breast cancer cell survival by Xanthohumol via modulation of the Notch signaling pathway in vivo and in vitro. Oncol Lett 15: 908-916, 2018.

59. Gan RH, Lin LS, Xie J, Huang L, Ding LC, Su BH, Peng XE, Zheng DL and Lu YG: FLI-06 intercepts notch signaling and suppresses the proliferation and self-renewal of tongue cancer cells. Onco Targets Ther 12: 7663-7674, 2019.

60. Dai L, He J, Liu Y, Byun J, Vivekanandan A, Pennathur S, Fan $X$ and Lubman DM: Dose-dependent proteomic analysis of glioblastoma cancer stem cells upon treatment with $\gamma$-secretase inhibitor. Proteomics 11: 4529-4540, 2011. 
61. Tammam J,Ware C,Efferson C,O'Neil J,Rao S,QuX,Gorenstein J, Angagaw M, Kim H, Kenific C, et al: Down-regulation of the Notch pathway mediated by a gamma-secretase inhibitor induces anti-tumour effects in mouse models of T-cell leukaemia. $\mathrm{Br}$ J Pharmacol 158: 1183-1195, 2009.

62. Tanaka M, Setoguchi T, Hirotsu M, Gao H, Sasaki H, Matsunoshita Y and Komiya S: Inhibition of Notch pathway prevents osteosarcoma growth by cell cycle regulation. $\mathrm{Br}$ J Cancer 100: 1957-1965, 2009.

63. Li ZL, Chen C, Yang Y, Wang C, Yang T, Yang X and Liu SC: Gamma secretase inhibitor enhances sensitivity to doxorubicin in MDA-MB-231 cells. Int J Clin Exp Pathol 8: 4378-4387, 2015.

64. Liu X, Xu QR, Xie WF and Wang MD: DAPT suppresses the proliferation of human glioma cell line SHG-44. Asian Pac J Trop Med 7: 552-556, 2014.

65. Li H, Li D and Meng N: Effects of RUNX3 mediated Notch signaling pathway on biological characteristics of colorectal cancer cells. Int J Oncol 50: 2059-2068, 2017.

66. He G, Mu T, Yuan Y, Yang W, Zhang Y, Chen Q, Bian M, Pan Y, Xiang Q, Chen $\mathrm{Z}$ and Sun A: Effects of notch signaling pathway in cervical cancer by curcumin mediated photodynamic therapy and its possible mechanisms in vitro and in vivo. $\mathrm{J}$ Cancer 10 4114-4122, 2019

67. Peng X, Zhou J, Li B, Zhang T, Zuo Y and Gu X: Notch1 and PI3K/Akt signaling blockers DAPT and LY294002 coordinately inhibit metastasis of gastric cancer through mutual enhancement. Cancer Chemother Pharmacol 85: 309-320, 2020.

68. Zhao ZL, Zhang L, Huang CF, Ma SR, Bu LL, Liu JF, Yu GT, Liu B, Gutkind JS, Kulkarni AB, et al: NOTCH1 inhibition enhances the efficacy of conventional chemotherapeutic agents by targeting head neck cancer stem cell. Sci Rep 6: 24704, 2016.
69. Qin J, Wang R, Zhao C, Wen J, Dong H, Wang S, Li Y, Zhao Y, Li J, Yang Y, et al: Notch signaling regulates osteosarcoma proliferation and migration through Erk phosphorylation. Tissue Cell 59: 51-61, 2019.

70. Tian Q, Xue Y, Zheng W, Sun R, Ji W, Wang X and An R: Overexpression of hypoxia-inducible factor $1 \alpha$ induces migration and invasion through Notch signaling. Int J Oncol 47: 728-738, 2015.

71. Jiang LY, Zhang XL, Du P and Zheng JH: $\gamma$-Secretase Inhibitor, DAPT inhibits self-renewal and stemness maintenance of ovarian cancer stem-like cells in vitro. Chin J Cancer Res 23: 140-146, 2011.

72. Ji Q, Hao X, Zhang M, Tang W, Yang M, Li L, Xiang D, Desano JT, Bommer GT, Fan D, et al: MicroRNA miR-34 inhibits human pancreatic cancer tumor-initiating cells. PLoS One 4: e6816, 2009.

73. de Antonellis P, Medaglia C, Cusanelli E, Andolfo I, Liguori L, De Vita G, Carotenuto M, Bello A, Formiggini F, Galeone A, et al: MiR-34a targeting of Notch ligand delta-like 1 impairs CD15+/CD133+ tumor-propagating cells and supports neural differentiation in medulloblastoma. PLoS One 6: e24584, 2011.

74. Wang J, Wang C, Meng Q, Li S, Sun X, Bo Y and Yao W: siRNA targeting Notch-1 decreases glioma stem cell proliferation and tumor growth. Mol Biol Rep 39: 2497-2503, 2012. International (CC BY-NC-ND 4.0) License. 